\title{
Article
}

\section{Immuno-PET Molecular Imaging of RANKL in Cancer}

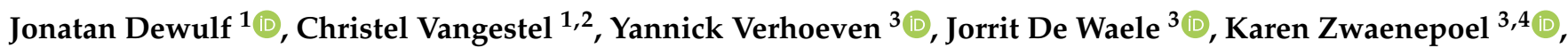 \\ Peter A. van Dam ${ }^{3,5}$, Filipe Elvas ${ }^{1}$ (D) and Tim Van den Wyngaert ${ }^{1,2, *(\mathbb{D})}$
}

1 Molecular Imaging Center Antwerp (MICA), Integrated Personalized and Precision Oncology Network (IPPON), Faculty of Medicine and Health Sciences, University of Antwerp, Universiteitsplein 1, B-2610 Wilrijk, Belgium; jonatan.dewulf@uantwerpen.be (J.D.); christel.vangestel@uantwerpen.be (C.V.); filipe.elvas@uantwerpen.be (F.E.)

2 Nuclear Medicine, Antwerp University Hospital, Drie Eikenstraat 655, B-2650 Edegem, Belgium

3 Center for Oncological Research (CORE), Integrated Personalized and Precision Oncology Network (IPPON), Faculty of Medicine and Health Sciences, University of Antwerp, Universiteitsplein 1,

B-2610 Wilrijk, Belgium; Yannick.Verhoeven@uantwerpen.be (Y.V.); Jorrit.DeWaele@uantwerpen.be (J.D.W.); Karen.Zwaenepoel@uza.be (K.Z.); peter.vandam@uza.be (P.A.v.D.)

4 Laboratory of Pathological Anatomy, Antwerp University Hospital, Drie Eikenstraat 655, B-2650 Edegem, Belgium

5 Multidisciplinary Oncologic Centre Antwerp (MOCA), Antwerp University Hospital, Drie Eikenstraat 655, B-2650 Edegem, Belgium

* Correspondence: tim.vandenwyngaert@uantwerpen.be

check for updates

Citation: Dewulf, J.; Vangestel, C.; Verhoeven, Y.; De Waele, J.; Zwaenepoel, K.; van Dam, P.A.; Elvas, F.; Van den Wyngaert, T. ImmunoPET Molecular Imaging of RANKL in Cancer. Cancers 2021, 13, 2166. https://doi.org/10.3390/ cancers13092166

Academic Editor: Antonia Dimitrakopoulou-Strauss

Received: 22 March 2021

Accepted: 27 April 2021

Published: 30 April 2021

Publisher's Note: MDPI stays neutral with regard to jurisdictional claims in published maps and institutional affiliations.

Copyright: (c) 2021 by the authors. Licensee MDPI, Basel, Switzerland. This article is an open access article distributed under the terms and conditions of the Creative Commons Attribution (CC BY) license (https:/ / creativecommons.org/licenses/by/ $4.0 /)$.
Simple Summary: Receptor activator of the nuclear factor kappa B ligand (RANKL) has been recently identified as a target of interest in the tumor microenvironment (TME), specifically in facilitating an immunosuppressive environment and subsequent resistance to immunotherapy. However, assessment of RANKL in the TME remains difficult due to its heterogeneous nature and suboptimal sampling methods. In our study we developed an anti-RANKL immuno-PET tracer to non-invasively monitor RANKL expression in the TME and help to understand the RANK/RANKL pathway.

Abstract: Purpose: The involvement of RANK/RANKL signaling in the tumor microenvironment (TME) in driving response or resistance to immunotherapy has only very recently been recognized. Current quantification methods of RANKL expression suffer from issues such as sensitivity, variability, and uncertainty on the spatial heterogeneity within the TME, resulting in conflicting reports on its reliability and limited use in clinical practice. Non-invasive molecular imaging using immuno-PET is a promising approach combining superior targeting specificity of monoclonal antibodies ( $\mathrm{mAb}$ ) and spatial, temporal and functional information of PET. Here, we evaluated radiolabeled anti-RANKL mAbs as a non-invasive biomarker of RANKL expression in the TME. Experimental design: Antihuman RANKL mAbs (AMG161 and AMG162) were radiolabeled with ${ }^{89} \mathrm{Zr}$ using the bifunctional chelator DFO in high yield, purity and with intact binding affinity. After assessing the biodistribution in healthy CD-1 nude mice, [ ${ }^{89} \mathrm{Zr}$ ]Zr-DFO-AMG162 was selected for further evaluation in ME-180 (RANKL-transduced), UM-SCC-22B (RANKL-positive) and HCT-116 (RANKL-negative) human cancer xenografts to assess the feasibility of in vivo immuno-PET imaging of RANKL. Results: $\left[{ }^{89} \mathrm{Zr}\right] \mathrm{Zr}$-DFO-AMG162 was selected as the most promising tracer for further validation based on biodistribution experiments. We demonstrated specific accumulation of [ ${ }^{89} \mathrm{Zr}$ ]Zr-DFO-AMG162 in RANKL transduced ME-180 xenografts. In UM-SCC-22B xenograft models expressing physiological RANKL levels, $\left[{ }^{89} \mathrm{Zr}\right.$ ]Zr-DFO-AMG162 imaging detected significantly higher signal compared to control [ $\left.{ }^{89} \mathrm{Zr}\right] \mathrm{Zr}$-DFO-IgG2 and to RANKL negative HCT-116 xenografts. There was good visual agreement with tumor autoradiography and immunohistochemistry on adjacent slides, confirming these findings. Conclusions: $\left[{ }^{89} \mathrm{Zr}\right.$ ]Zr-DFO-AMG162 can detect heterogeneous RANKL expression in the TME of human cancer xenografts, supporting further translation of RANKL immuno-PET to evaluate tumor RANKL distribution in patients.

Keywords: RANKL; antibody; PET; tumor microenvironment 


\section{Introduction}

The receptor activator of nuclear factor kappa B ligand (RANKL) and its receptor RANK are members of the tumor necrosis factor (TNF) and TNF receptor (TNFR) superfamily. The binding of RANKL to RANK results in the trimerization of the receptor and recruitment of TNF receptor-associated factors (TRAF), adaptor proteins, and activation of downstream signaling pathways [1]. The RANKL/RANK system was initially discovered during research into TNFR homologs expressed on T cells and dendritic cells [2]. Subsequently, the RANK/RANKL interaction's pivotal role in osteoclastogenesis and bone homeostasis was elucidated [3]. RANKL binds osteoprotegerin (OPG) and the leucinerich repeat-containing G-protein coupled receptor 4 (LGR4), resulting in an inhibition of downstream signaling and acting as a negative feedback mechanism preventing excess activation. These findings have led to the development of RANKL-targeting therapies, of which the fully human monoclonal antibody denosumab has been in clinical use for almost a decade. Indeed, denosumab has proven benefits for patients with osteoporosis, cancer-related bone disease, and other skeletal conditions [4-6].

More recently, RANK/RANKL signaling was also found to be an essential component in carcinogenesis, specifically in the maintenance of self-renewal of cancer stem cells and up-regulation of anti-apoptotic pathways, making the RANK/RANKL axis an attractive therapeutic target [7]. Moreover, inhibiting RANKL has been shown to improve the effectiveness of immune-checkpoint inhibitors (ICI) targeting CTLA-4 or PD(L)- 1 in preclinical models of cancer [8,9]. While immunotherapy has revolutionized contemporary oncology, it is typically only beneficial in a small subset of patients. This limitation of ICIs has fueled interest in an improved understanding of the intricate interplay of cancer cells, immune cells and cytokines in the tumor microenvironment (TME) [10]. To this end, current methods to assess RANKL expression typically include serum assays or ex vivo immunohistochemistry (IHC) of tissue biopsies. However, these techniques are hampered by issues with sensitivity, variability, and spatial heterogeneity within the TME and negatively impact patient comfort when tissue sampling is required, if tissue sampling is even remotely possible [11,12]. Immuno-positron emission tomography (PET) can provide solutions to the problems above by combining the superior sensitivity of PET with the benefits of high targeting specificity of monoclonal antibodies, which can provide information on whole-body biomarker distribution or tumor target expression and act as a companion diagnostic in vivo in a non-invasive and longitudinal manner.

We aimed to develop a non-invasive imaging biomarker using PET to study the expression and spatial heterogeneity of tumor expressed RANKL in the TME. In particular, ${ }^{89} \mathrm{Zr}$-anti-RANKL radioimmunoconjugates were synthesized in a reproducible way, characterized for antigen affinity and optimal biodistribution, and validated as markers of RANKL expression and heterogeneity in the TME in human cancer xenograft models.

\section{Materials and Methods}

2.1. Bioconjugation and Radiolabeling of RANKL-Targeted Monoclonal Antibodies (RANKL mAbs)

The human RANKL-targeting human monoclonal antibodies (mAbs) AMG161 (IgG1; Amgen Inc., Thousand Oaks, CA, USA) and AMG162 (human antibody; IgG2; denosumab (XGEVA), Amgen Inc., Thousand Oaks, CA, USA), and control IgG2 isotype (SigmaAldrich Cat\# I5404, RRID:AB_1163681, Saint Louis, MO, USA) were modified with the bifunctional chelator deferoxamine (DFO/p-SCN-Bn-DFO, Macrocyclics, Plano, TX, USA). Briefly, unconjugated $\mathrm{mAbs}$ were prepared at $3 \mathrm{mg} / \mathrm{mL}$ in phosphate-buffered saline $0.01 \mathrm{M}, \mathrm{pH}$ 7.4 (PBS), buffer-exchanged with PBS solution and $\mathrm{pH}$ adjusted to 8.8-9.2 with $0.1 \mathrm{M} \mathrm{Na}_{2} \mathrm{CO}_{3}$ (Sigma Aldrich, St. Louis, MO, USA). Next, a 5-fold molar excess DFO was added to the AMG161, AMG162 and isotype IgG2 solutions and the conjugation was allowed to proceed for $1 \mathrm{~h}$ (AMG162) and $2 \mathrm{~h}$ (AMG161) at $37^{\circ} \mathrm{C}$ with gentle agitation. Subsequently, the reaction mixture was purified using a PD-10 size exclusion column (Cytiva, Marlborough, MA, USA) and buffer-exchanged with PBS to remove unconjugated 
DFO using a $2 \mathrm{~mL}$ Amicon centrifugal filter unit with a $50 \mathrm{kDa}$ cutoff (Merck, Darmstadt, Germany). The concentration of the final DFO-AMG161, -AMG162 and -IgG2 conjugates was determined via UV-VIS absorbance at $280 \mathrm{~nm}$ using a spectrophotometer (Genesys $10 \mathrm{~S}$ UV-VIS, Thermo Fisher Scientific, Waltham, MA, USA).

The loading efficiency of the DFO chelates in the final bioconjugates was determined by ESI mass spectrometer (Centre for Proteomics, University of Antwerp) using a Q-TOF2 instrument (Waters, Milford, MA, USA), as previously described [13].

For ${ }^{89} \mathrm{Zr}$ labeling, $185 \mathrm{MBq}$ of ${ }^{89} \mathrm{Zr}$-oxalate (BV cyclotron VU, Perkin Elmer, Waltham, MA, USA) was diluted to $0.2 \mathrm{~mL}$ with $1 \mathrm{M}$ oxalic acid (Sigma Aldrich, St. Louis, MO, USA), neutralized with $2 \mathrm{M} \mathrm{Na}_{2} \mathrm{CO}_{3}$ (Sigma Aldrich, St. Louis, MO, USA) and added to chelex-treated HEPES buffer (0.5 M, pH 7.2, Sigma Aldrich, St. Louis, MO, USA). This was followed by the addition of $1 \mathrm{mg}$ of DFO-AMG162 or DFO-IgG2, or $0.75 \mathrm{mg}$ of DFO-AMG161, and volume adjustment to $2 \mathrm{~mL}$ with HEPES buffer. Radiolabeling was performed for $1 \mathrm{~h}$ at $37^{\circ} \mathrm{C}$, after which the radiolabeled antibodies were purified using a PD10 desalting column and concentrated using Amicon centrifugal filter units (cutoff $50 \mathrm{kDa}$ ). The radiochemical yield and purity were evaluated by size exclusion chromatographyhigh performance liquid chromatography (SEC-HPLC, Cytiva, Marlborough, MA, USA, Superdex 200 increase 5/150, phosphate buffer $0.05 \mathrm{M} \mathrm{pH} 6.7, \lambda=280 \mathrm{~nm}$ ) and instant thinlayer chromatography (iTLC, Elysia, Angleur, Belgium glass microfiber chromatography paper impregnated with a silica gel (SG), $20 \mathrm{mM}$ citric acid/acetonitrile $(9: 1,(v / v))$. iTLC strips were cut in half, and the bottom and top parts were counted for radioactivity in an automatic gamma-counter (Wizard 2480, PerkinElmer, Waltham, MA, USA). Radiolabeled antibody remained at the origin (Rf $\left[{ }^{89} \mathrm{Zr}\right] \mathrm{Zr}$-DFO-Antibody $=0$ ), while free ${ }^{89} \mathrm{Zr}$ and ${ }^{89} \mathrm{Zr}$-DFO moved with the solvent front $(\mathrm{Rf}=1)$. The concentration of the radiolabeled antibody in the final PBS formulation was calculated using a spectrophotometer (Genesys $10 S \mathrm{UV}-\mathrm{VIS}, \lambda=280 \mathrm{~nm}$ ), which was used to calculate the specific activity.

The radiotracers' stability was evaluated over seven days in vitro by incubation in the final formulation (PBS) at room temperature and in human plasma and mouse plasma at $37^{\circ} \mathrm{C}$. Samples were spotted on TLC strips, and subsequent iTLC analysis was performed as described above.

The immunoreactivity of DFO-AMG161 and DFO-AMG162 was determined by using a non-cell based binding assay, as previously described [14].

\subsection{Mice}

Immunodeficient CD-1 nude female mice (Charles River Laboratories, Wilmington, MA, USA, RRID:IMSR_CRL:086), age 5-7 weeks, weight 20-25 g, were kept under environmentally controlled conditions (12 h light/dark cycle, $20-24^{\circ} \mathrm{C}$ and $40-70 \%$ relative humidity) in individually ventilated cages with food and water ad libitum. Experimental procedures and protocols were performed following European Directive 86/609/EEC Welfare and Treatment of Animals and were approved by the local ethical committee (2018-48, University of Antwerp, Belgium). Sample size was estimated by power analysis ( $\alpha=0.05$, power 0.8 ) and animals were assigned to experimental groups using simple randomization.

\subsection{Ex Vivo Biodistribution}

Mice $(n=4)$ were injected intravenously (i.v.) in the lateral tail vein with $\left[{ }^{89} \mathrm{Zr}\right] \mathrm{Zr}$-DFOAMG161 (14 $\pm 0.7 \mu \mathrm{g} ; \sim 3.3 \mathrm{MBq} ; n=20)$ or [ $\left.{ }^{89} \mathrm{Zr}\right] \mathrm{Zr}$-DFO-AMG162 $(14 \pm 0.7 \mu \mathrm{g} ; \sim 2.2 \mathrm{MBq}$; $n=20)$ in $200 \mu \mathrm{L}$ sterile saline $(0.9 \% \mathrm{NaCl})$. On days $1,2,3,4$ and 7 after radiotracer injection, blood was collected via cardiac puncture, and the mice were euthanized via cervical dislocation. Subsequently, blood, heart, lungs, liver, spleen, pancreas, stomach, small intestine, large intestine, kidneys, bladder, urine, muscle, fat, bone, brain and skin were harvested, weighed, and the radioactivity was measured using an automatic gammacounter (Wizard 2480, PerkinElmer, Waltham, MA, USA). Uptake levels of the radiotracers were expressed as a percentage of the injected dose per gram $(\% \mathrm{ID} / \mathrm{g})$. The radiotracer 
demonstrating the most favorable biodistribution was selected for subsequent xenograft experiments.

\subsection{Xenograft Tumor Models}

The HCT-116 human colorectal carcinoma cell line (ATCC Cat\# CCL-247, RRID:CVCL_ 0291), the UM-SCC-22B human head and neck squamous carcinoma cell line (Laboratory of Experimental Cancer Research, Ghent University Hospital, Ghent, Belgium, RRID:CVCL_7732), and the ME-180 human cervical squamous carcinoma cell line (ATCC Cat\# HTB-33, RRID:CVCL_1401) were selected for xenograft transplantation. The ME180 cell line was transduced with human RANKL (\#LTV2504, G\&P Biosciences, Santa Clara, CA, USA) and selected with $4 \mathrm{mg} / \mathrm{mL}$ G418/Geneticin (ant-gn-1, InvivoGen Europe, Toulouse, France) for 5 days and will be referred to as ME-180-RANKL in the manuscript from hereon.

The HCT-116 and ME-180-RANKL cell lines were cultured in McCoy's 5A modified medium (Invitrogen), and the UM-SCC-22B cell line was cultured in Dulbecco's Modified Eagle medium (Invitrogen), both media were supplemented with $10(v / v \%)$ fetal bovine serum (FBS) (Invitrogen), $2 \mathrm{mM}$ L-glutamine (Invitrogen), and $1(\mathrm{~m} / \mathrm{m} \%)$ penicillin and streptomycin (Invitrogen). Cells were incubated at $37{ }^{\circ} \mathrm{C}$ in humidified conditions with $5 \%$ $\mathrm{CO}_{2}$. Cells were passaged and harvested using a $0.05 \%$ trypsin/EDTA solution.

The transduction efficiency was estimated by assessing RANKL expression using flow cytometry on a BD FACSAria II (BD Biosciences, San Jose, CA, USA) cytometer with an APC-conjugated antibody (\#347508, Biolegend, San Diego, CA, USA). Positivity was determined using the overton algorithm.

Low-passage UM-SCC-22B $\left(5 \times 10^{6}\right)$, HCT-116 $\left(5 \times 10^{6}\right)$ and ME-180-RANKL $\left(8 \times 10^{6}\right)$ cells were harvested, suspended in $100 \mu \mathrm{L}$ sterile PBS and subcutaneously injected into the right hindlimb of athymic female CD-1 nude mice (Charles River Laboratories RRID:IMSR CRL:086). When the tumors became palpable, tumor growth was evaluated 3 times/week using caliper measurements. Tumor volume was calculated according to the formula $0.5 \times\left(\right.$ length $\times$ width $\left.^{2}\right)$.

Animals were eligible for the experimental design in the imaging study when tumor volume reached $100 \mathrm{~mm}^{3}$. Tumor bearing animal in which tumor growth was halted or did not exceed $100 \mathrm{~mm}^{3}$ were excluded from the study.

\subsection{PET Imaging}

Tumor-bearing mice were injected i.v. with [ $\left.{ }^{89} \mathrm{Zr}\right] \mathrm{Zr}$-DFO-AMG162 $(73 \pm 1.5 \mu \mathrm{g}$; $\sim 10.5 \mathrm{MBq} /$ mouse; $n=4-5)$ or $\left.{ }^{89} \mathrm{Zr}\right] \mathrm{Zr}$-DFO-IgG2 isotype control (75 $\pm 1.5 \mu \mathrm{g}$ in $200 \mu \mathrm{L}$ sterile saline; $\sim 11.7 \mathrm{MBq} /$ mouse; $n=5$ ) via lateral tail vein injection. A blocking study was performed to confirm the binding specificity of $\left[{ }^{89} \mathrm{Zr}\right] \mathrm{Zr}$-DFO-AMG162. For this, mice bearing ME-180-RANKL xenografts $(n=5)$ were i.v. injected via the tail vein with a $50 \times$ excess dose of native (unconjugated and non-radioactive) AMG162 (3.75 mg, $150 \mu \mathrm{L})$ one day prior to radiotracer injection. PET/Computed Tomography (CT) images were acquired at $72 \mathrm{~h}$ and $120 \mathrm{~h}$ post-injection (p.i). Before image acquisition, mice were anesthetized using isoflurane ( $5 \%$ for induction, $2 \%$ for maintenance). Static whole-body PET images were acquired over 25 to 35 min using an Inveon small-animal PET/CT scanner (Siemens Healthineers, Erlangen, Germany). Following each PET acquisition, a whole-body CT scan of $10 \mathrm{~min}$ was acquired to obtain anatomic information for segmentation. Throughout the entire PET/CT scanning procedure, the mice were maintained at constant body temperature using a heating pad, and breathing was continuously monitored.

For quantitative analysis, volumes of interest were manually drawn on the PET images using PMOD (PMOD, v 3.6; PMOD Technologies, RRID:SCR_016547) to delineate the tumors. For an absolute measure of tracer uptake, normalized images were scaled according to the percent injected dose $(\% \mathrm{ID} / \mathrm{mL}=$ tissue uptake $[\mathrm{kBq} / \mathrm{mL}] /$ injected dose $[\mathrm{kBq}] \times 100 \%)$. After the last PET /CT imaging acquisition, mice were sacrificed via cervical dislocation, and ex vivo biodistribution was performed as described earlier. 


\subsection{Autoradiography and Immunohistochemistry Analysis}

After gamma-counting, the tumors were rapidly snap-frozen in tissue-Tek (OCT compound; VWR, Radnor, PA, USA), sectioned $(100 \mu \mathrm{m})$ using cryostat (Leica Biosystems, CM1950, Wetzlar, Germany), and exposed overnight to phosphor screen plates (Fujifilm, Tokio, Japan). Exposed plates were imaged in a phosphor imager system (Typhoon FLA7000; GE Healthcare, Cytiva, Marlborough, MA, USA) to visualize regional tracer distribution as qualitative measure. Image analysis occurred via ImageJ v1.53 (RRID:SCR_003070) and underwent pseudo-coloring transformation.

Moreover, adjacent frozen tumor sections $(10 \mu \mathrm{m})$ were taken at regular intervals across the entire tumor volume and used for histologic analysis of RANKL expression. Quantification of RANKL staining was performed by calculating the percentage of DABstained (brown) area across two non-sequential whole-tumor sections using the immunohistochemistry (IHC) profiler plugin for ImageJ v1.53 (RRID:SCR_003070), as previously described [15]. Three to five tumors were evaluated per tumor type. The mean percentage of positive stained area per tumor was used to calculate differences between groups. RANKL levels were correlated to the corresponding ex vivo radiotracer uptake in the tumor.

\subsection{Statistical Analysis}

The data are presented as mean $\% \pm$ one standard deviation (SD). Graphs, twotailed unpaired $t$-tests, Pearson correlation and linear regression analysis were performed with GraphPad Prism version 6.01 (RRID:SCR_002798). $p$ value $<0.05$ was considered as statistically significant.

\section{Results}

\subsection{Bioconjugation, Characterization, and Radiolabeling Of AMG161 and AMG162}

We have developed two radiolabeled human mAbs AMG161 (IgG1) and AMG162 (IgG2), both targeting human RANKL. Radioimmunoconjugates were generated via a random amine conjugation strategy, using a DFO macrocyclic chelator. DFO-modified RANKL targeting (AMG161 and AMG162) immunoconjugates were analyzed by ESIQTOF2 mass spectrometry analysis, indicating that conjugations yielded between 0 and 3 DFO chelators bound to AMG161 and AMG162 (Figure S1A,B).

A binding assay was performed to confirm the conservation of the binding affinity to human RANKL of the DFO immunoconjugates. AMG161 (Kd 0.23 nM; 95\% CI 0.18-0.27), DFO-AMG161 (Kd 0.26 nM; 95\% CI 0.20-0.33), AMG162 (Kd 0.13 nM; 95\% CI 0.076-0.18) and DFO-AMG162 (Kd 0.26 nM; 95\% CI 0.041-0.17) showed similar binding affinity between native antibodies and their corresponding DFO immunoconjugates ( $\mathrm{Kd}=$ equilibrium dissociation constant between antibody and antigen). Binding specificity towards human RANKL was confirmed using a non-specific human IgG1, which showed a complete lack of binding, and using OPG (Kd 0.63 nM; 95\% CI 0.42-0.84) (Figure S2).

Radiolabeling of the DFO immunoconjugates with ${ }^{89} \mathrm{Zr}$ resulted in high radiochemical yield ([ $\left.{ }^{89} \mathrm{Zr}\right] \mathrm{Zr}$-DFO-AMG161: 95\%; [ $\left.{ }^{89} \mathrm{Zr}\right] \mathrm{Zr}-\mathrm{DFO}-\mathrm{AMG162:} 78 \%$, non-decay corrected), purity $(>99 \%)$ and specific activity ([ $\left.{ }^{89} \mathrm{Zr}\right] \mathrm{Zr}-\mathrm{DFO}-\mathrm{AMG161:} 240 \mathrm{MBq} / \mathrm{mg}$; [ $\left.{ }^{89} \mathrm{Zr}\right] \mathrm{Zr}$-DFOAMG162: $152 \pm 22 \mathrm{MBq} / \mathrm{mg}$ ). The isotype control, [ $\left.{ }^{89} \mathrm{Zr}\right] \mathrm{Zr}-\mathrm{DFO}-\mathrm{IgG}$, showed a radiochemical yield of $95 \%$ (non-decay corrected), a purity of $>99 \%$ and specific activity of $157 \mathrm{MBq} / \mathrm{mg}$.

Both radiotracers remained stable in PBS, human and mouse plasma measured up to 7 days in vitro (Figure S3A,B).

\subsection{Biodistribution of Both Radiotracers in Healthy CD-1 Nude Mice}

Differences in the biodistribution between the IgG1 and IgG2 isotype of the radiotracer were evaluated in vivo during 7 days in CD-1 nude mice. $\left[{ }^{89} \mathrm{Zr}\right] \mathrm{Zr}$-DFO-AMG162 showed an expected and slow antibody clearance from the blood, while undesirable non-specific radiotracer uptake in various organs was absent (Figure 1A, Table S1). In contrast, $\left[{ }^{89} \mathrm{Zr}\right] \mathrm{Zr}$ DFO-AMG161 demonstrated immediate high and variable sequestration in the liver and 
spleen in the majority of animals, clearing the antibody from circulation and undesirably reducing the exposure time of the radiotracer to a potential target (Figure 1B, Table S2). In light of these suboptimal findings, [ $\left.{ }^{89} \mathrm{Zr}\right] \mathrm{Zr}$-DFO-AMG161 was not further explored in subsequent xenograft experiments. On the other hand $\left.{ }^{89} \mathrm{Zr}\right] \mathrm{Zr}$-DFO-AMG162 showed favorable biodistribution and good characteristics as potential radiotracer.
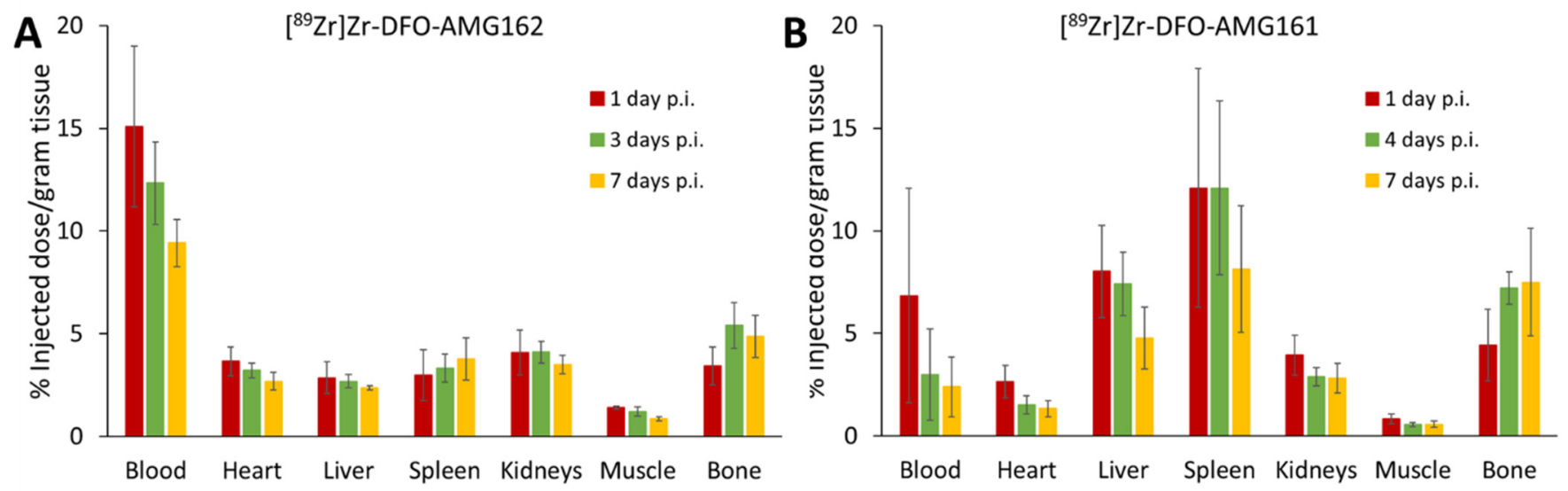

Figure 1. Ex vivo biodistribution of (A) $\left[{ }^{89} \mathrm{Zr}\right] \mathrm{Zr}-\mathrm{DFO}-\mathrm{AMG} 162$ and (B) $\left[{ }^{89} \mathrm{Zr}\right] \mathrm{Zr}$-DFO-AMG161 in healthy CD-1 nude mice $(n=4)$ during 7 days post injection (p.i.). (Animals per timepoint: $n=4$, data graph: mean $+/-1$ standard deviation).

\section{3. [89. Zr]Zr-DFO-AMG162 PET Imaging Studies in ME-180-RANKL Transduced Subcutaneous Xenografts}

The in vivo targeting potential of $\left.{ }^{89} \mathrm{Zr}\right] \mathrm{Zr}$-DFO-AMG162 was assessed in xenografts of the RANKL transduced ME-180 cell line. The ME-180-RANKL cell line was characterized using flow cytometry showing high RANKL expression ( $82.4 \%$ overton) compared to the non-transduced cell line (4.5\% overton).

$\left[{ }^{89} \mathrm{Zr}\right] \mathrm{Zr}$-DFO-AMG162 demonstrated a peak mean standardized uptake value (SUV mean) of $5.80 \pm 0.40 \mathrm{~g} / \mathrm{mL}$ at day 5 , as shown in Figure $2 \mathrm{~A}, \mathrm{~B}$. The specificity of $\left[{ }^{89} \mathrm{Zr}\right] \mathrm{Zr}-\mathrm{DFO}-$ AMG162 was evaluated in a blocking study. Pre-injection of 50× excess native AMG162 significantly blocked radiotracer uptake in ME-180-RANKL tumors $(1.98 \pm 0.14 \mathrm{~g} / \mathrm{mL}$ at day $5 ; p<0.0001$ ).

The ex vivo assessed biodistribution profile was measured at day 5 p.i. and showed a significantly higher radiotracer uptake (26.2 $\pm 3.3 \%$ ID/g; Figure 2C) in ME-180-RANKL xenografts when compared to blocked tumors $(9.0 \pm 1.6 \% \mathrm{ID} / \mathrm{g} ; p<0.0001)$. Significantly different radiotracer uptake between blocked and non-blocked xenografts could be observed in blood $(p=0.0007)$, heart $(p=0.0011)$, spleen $(p=0.0063)$, kidney $(p=0.0117)$ and muscle $(p=0.0216)$. The ex vivo biodistribution profile of $\left[{ }^{89} \mathrm{Zr}\right] \mathrm{Zr}$-DFO-AMG162 is summarized in Tables S3 and S4.

High tumor-to-organ ratios for $\left[{ }^{89} \mathrm{Zr}\right] \mathrm{Zr}$-DFO-AMG162 were observed in non-blocked ME-180-RANKL xenografts compared to the same xenografts with co-administration of a blocking dose Table 1 .

Table 1. Tumor-to-organ ratio of [ $\left.{ }^{89} \mathrm{Zr}\right] \mathrm{Zr}$-DFO-AMG162 5 days post injection in mice bearing ME180 -RANKL blocked $(n=5)$ and non-blocked $(n=5)$ xenografts. Data is shown below as mean \pm the standard deviation.

\begin{tabular}{cccc}
\hline Tumor/Organ Ratio & Blood & Muscle & Bone \\
\hline ME-180-RANKL & $4.5 \pm 0.7$ & $43.3 \pm 4.6$ & $3.7 \pm 0.4$ \\
\hline ME-180-RANKL + Blocking & $0.8 \pm 0.1$ & $9.3 \pm 3.1$ & $1.8 \pm 0.4$ \\
\hline
\end{tabular}


High correlation was observed between PET and ex vivo biodistribution measurements in the tumor $(r=0.99, p<0.0001)$. These results indicate that $\left[{ }^{89} \mathrm{Zr}\right] \mathrm{Zr}$-DFO-AMG162 enables non-invasive and specific detection of RANKL in vivo.

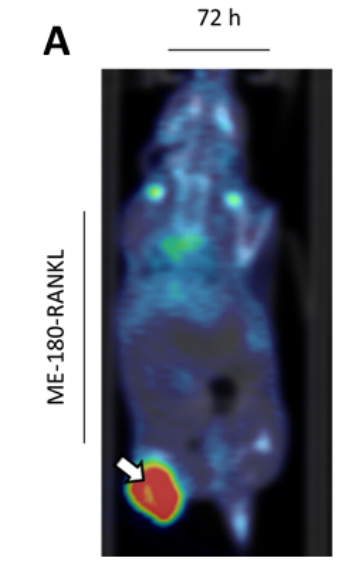

$72 \mathrm{~h}$

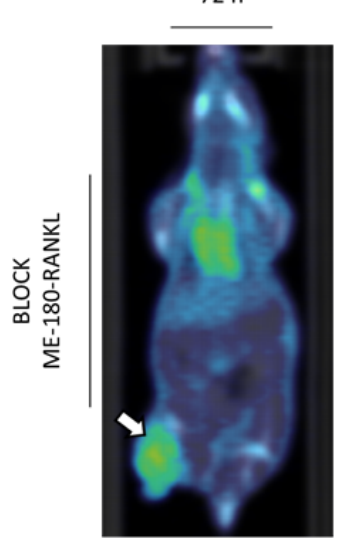

$120 \mathrm{~h}$

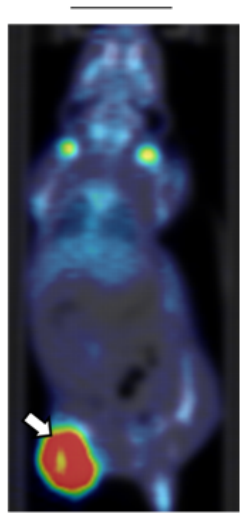

$120 \mathrm{~h}$

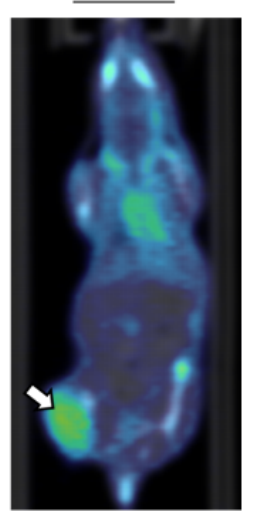

B

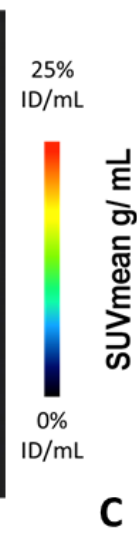

PET ME-180-RANKL

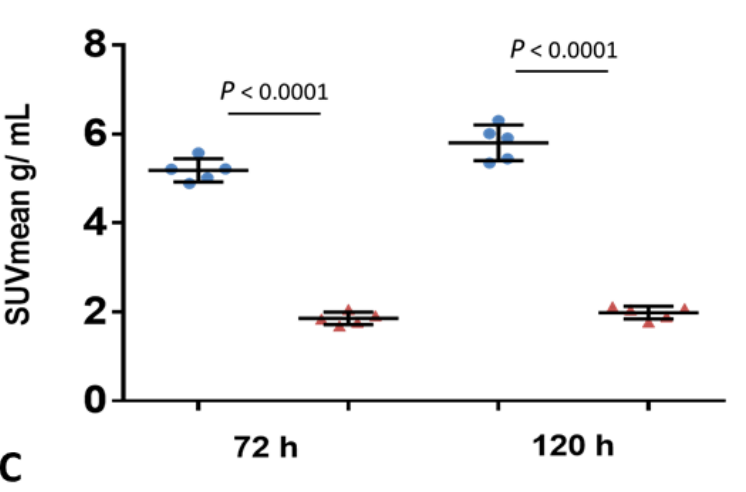

Ex vivo ME-180-RANKL

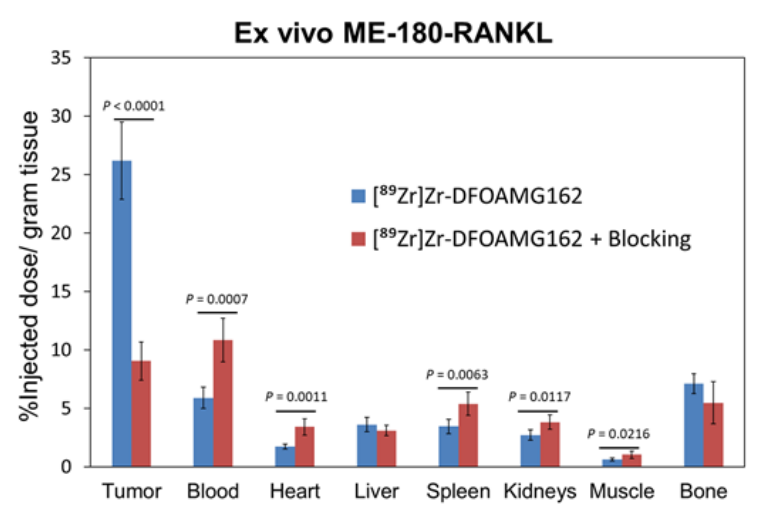

Figure 2. Overview imaging studies in ME-180-RANKL xenografts. (A) [ ${ }^{89} \mathrm{Zr}$ ]Zr-DFO-AMG162 PET imaging $72 \mathrm{~h}$ and $120 \mathrm{~h}$ post injection in ME-180-RANKL non-blocked (top) and blocked (bottom) xenografts (arrows). (B) Difference in tumor uptake (SUV mean $\mathrm{g} / \mathrm{mL}$ ) assessed via PET between ME-180-RANKL xenografts treated without or with blocking dose at $72 \mathrm{~h}$ and $120 \mathrm{~h}$ p.i. (C) Ex vivo assessment of $\left[{ }^{89} \mathrm{Zr}\right] \mathrm{Zr}$-DFO-AMG162 biodistribution (\% ID/g) at $120 \mathrm{~h}$ p.i. (Blue bars: $\left[{ }^{89} \mathrm{Zr}\right.$ ]Zr-DFO-AMG162 in non-blocked ME-180-RANKL xenografts, Red bars: $\left[{ }^{89} \mathrm{Zr}\right] \mathrm{Zr}-\mathrm{DFO}-\mathrm{AMG162}$ in blocked ME-180-RANKL xenografts, Animals per timepoint in both groups: $n=5$, Data graph: mean $+/-1$ standard deviation, White arrows: tumor, $\mathrm{SUV}_{\text {mean: }}$ mean standard uptake value, ID/mL: injected dose/mL, Statistical analysis: unpaired student $t$-test).

\section{4. [89. Zr]Zr-DFO-AMG162 Imaging Studies in Human Head and Neck Squamous UM-SCC-22B Subcutaneous Xenografts}

The final goal of this study was to assess the ability of $\left.{ }^{89} \mathrm{Zr}\right] \mathrm{Zr}$-DFO-AMG162 to image physiological RANKL expression with respect to expression levels and distribution to support further clinical translation. $\left[{ }^{89} \mathrm{Zr}\right] \mathrm{Zr}$-DFO-AMG162 was injected in mice bearing UM-SCC-22B human head and neck squamous cell carcinoma (positive RANKL) and HCT116 human colorectal cancer xenografts (negative RANKL control) tumors and PET/CT images were acquired at 3 and 5 days p.i. As non-targeted control, UM-SCC-22B xenografts were injected with $\left[{ }^{89} \mathrm{Zr}\right] \mathrm{Zr}$-DFO-IgG2 (non-specific human IgG2 isotype). PET/CT images at 5 days p.i. showed that $\left[{ }^{89} \mathrm{Zr}\right] \mathrm{Zr}-\mathrm{DFO}-\mathrm{AMG} 162$ uptake in the tumors at day 5 was significantly higher in UM-SCC-22B xenografts $\left(\mathrm{SUV}_{\text {mean }} 1.76 \pm 0.12 \mathrm{~g} / \mathrm{mL}, p=0.025\right)$ when compared with HCT-116 xenografts (SUV mean $1.52 \pm 0.13 \mathrm{~g} / \mathrm{mL}$ ) (Figure 3A,B). In addition, at day 5 we observed a significantly higher [ $\left.{ }^{89} \mathrm{Zr}\right] \mathrm{Zr}-\mathrm{DFO}-\mathrm{AMG} 162 \mathrm{SUV}$ mean $(1.76 \pm 0.12 \mathrm{~g} / \mathrm{mL}, p=0.0118)$ when compared with [ $\left.{ }^{89} \mathrm{Zr}\right] \mathrm{Zr}-\mathrm{DFO}-\mathrm{IgG} 2(1.50 \pm 0.11 \mathrm{~g} / \mathrm{mL})$ in UM-SCC-22B tumors, which confirmed selective [ $\left.{ }^{89} \mathrm{Zr}\right] \mathrm{Zr}-\mathrm{DFO}-\mathrm{AMG} 162$ uptake be- 
yond what can be explained by the enhanced permeability and retention (EPR) effect (Figure 3A,B). Radiotracer accumulation in other tissues was consistent with what was observed in the biodistribution experiments using healthy CD-1 nude mice.
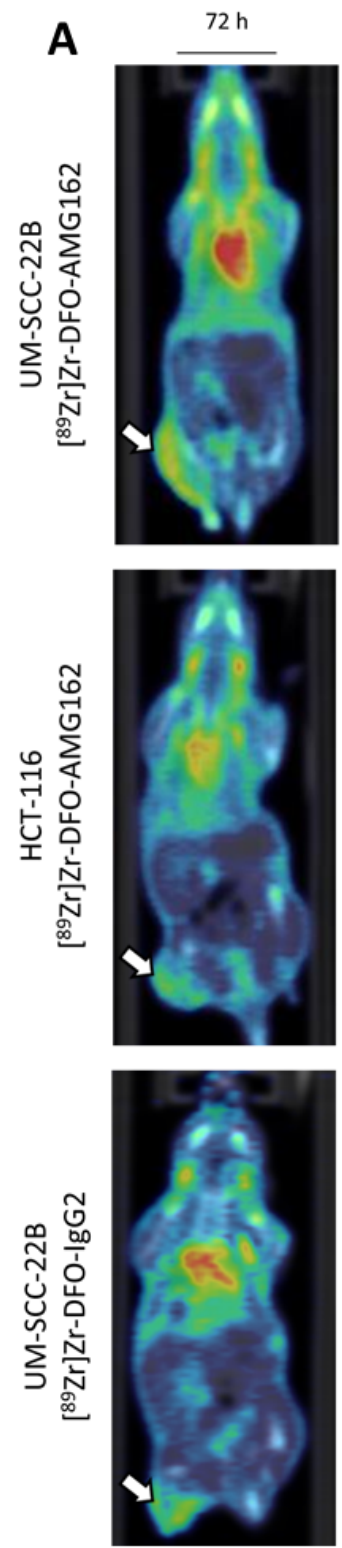

$120 \mathrm{~h}$
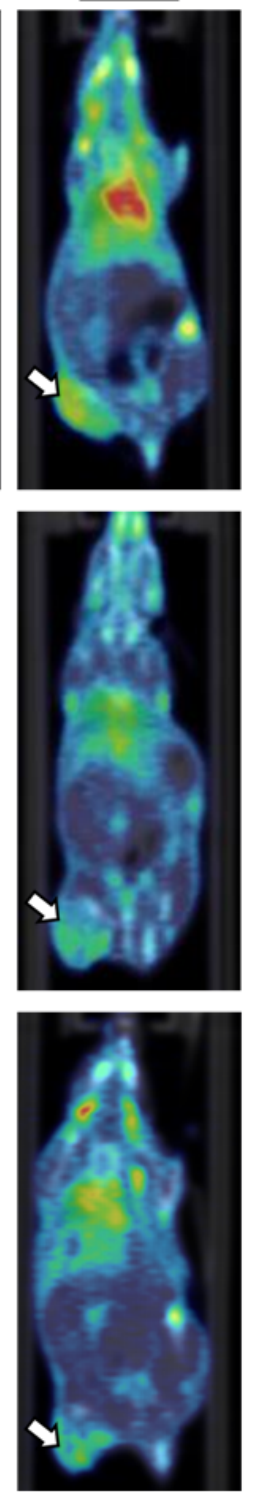

B

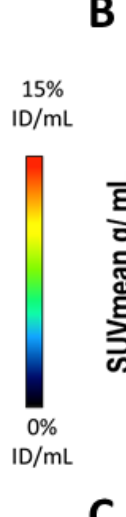

C

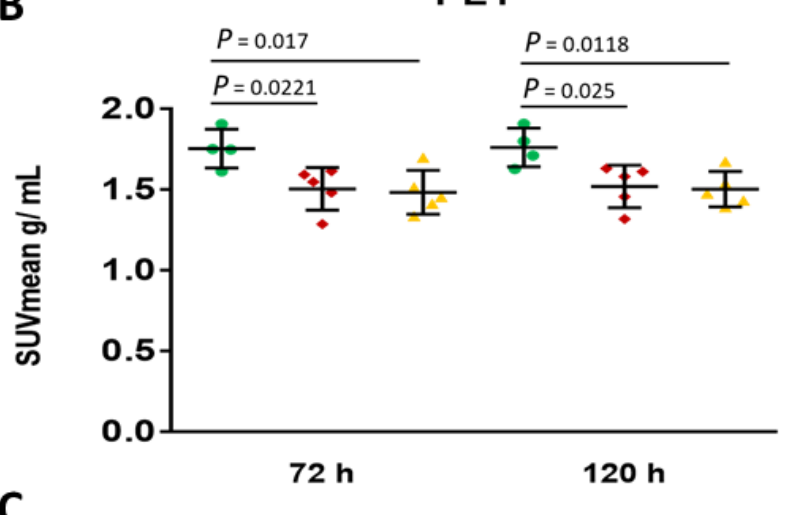

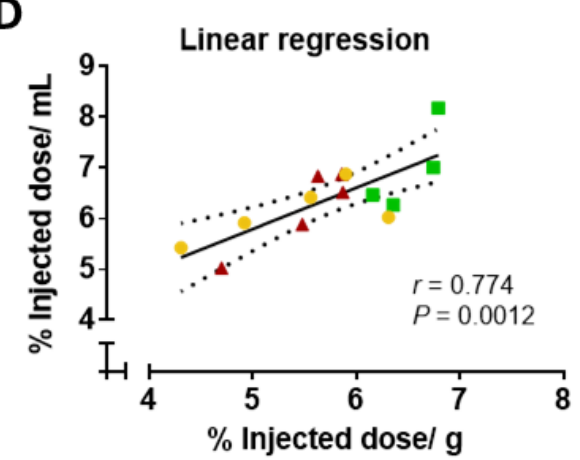

Figure 3. Overview imaging studies in UM-SCC-22B xenografts. (A) $\left[{ }^{89} \mathrm{Zr}\right] \mathrm{Zr}-\mathrm{DFO}-\mathrm{AMG} 162$ PET imaging in UM-SCC-22B (top) and HCT-116 xenografts (middle), and [ $\left.{ }^{89} \mathrm{Zr}\right] \mathrm{Zr}-\mathrm{DFO}-\mathrm{IgG} 2$ in UM-SCC-22B (bottom) at $72 \mathrm{~h}$ and $120 \mathrm{~h}$ p.i. (B) Difference in tumor uptake $\left(\mathrm{SUV}_{\text {mean }} \mathrm{g} / \mathrm{mL}\right)$ assessed via PET between UM-SCC-22B and HCT-116 xenografts imaged with $\left.{ }^{89} \mathrm{Zr}\right] \mathrm{Zr}-$ DFO-AMG162 or [ $\left.{ }^{89} \mathrm{Zr}\right] \mathrm{Zr}-\mathrm{DFO}-\mathrm{IgG} 2$ at $72 \mathrm{~h}$ and $120 \mathrm{~h}$ p.i. (C) Difference in tumor uptake as assessed ex vivo (\% ID/g) between $\left[{ }^{89} \mathrm{Zr}\right] \mathrm{Zr}$-DFO-AMG162 and [ $\left.{ }^{89} \mathrm{Zr}\right] \mathrm{Zr}-\mathrm{DFO}-\mathrm{IgG} 2$ in UM-SCC-22B and HCT116, and UM-SCC-22B xenografts, respectively. (D) Linear regression in UM-SCC-22B and HCT-116 xenografts between in vivo PET imaging and ex vivo measurements of [ $\left.{ }^{89} \mathrm{Zr}\right] \mathrm{Zr}$-DFO-AMG162 or [ $\left.{ }^{89} \mathrm{Zr}\right] \mathrm{Zr}-\mathrm{DFO}-\mathrm{IgG} 2(r=0.774, p=0.0012)$. (Green bars: $\left[{ }^{89} \mathrm{Zr}\right] \mathrm{Zr}-\mathrm{DFO}-\mathrm{AMG} 162$ in UM-SCC-22B xenografts, Red bars: $\left[{ }^{89} \mathrm{Zr}\right] \mathrm{Zr}-\mathrm{DFO}-\mathrm{AMG} 162$ in HCT-116 xenografts, Yellow bars: $\left[{ }^{89} \mathrm{Zr}\right] \mathrm{Zr}-\mathrm{DFO}-\mathrm{IgG} 2$ in UM-SCC-22B xenografts, Animals per timepoint in groups: $n=4-5$, Data graph: mean $+/-1$ standard deviation, White arrows: tumor, $\mathrm{SUV}_{\text {mean }}$ : mean standard uptake value, ID/mL: injected dose $/ \mathrm{mL}$, Statistical analysis: unpaired student t-test). 
To corroborate the PET results, ex vivo biodistribution analysis was performed at day 5 p.i., which confirmed significantly higher [ ${ }^{89} \mathrm{Zr}$ ]Zr-DFO-AMG162 uptake in UM-SCC22B xenografts $(6.5 \pm 0.3 \%$ ID $/ g)$ compared with HCT-116 xenografts $(5.5 \pm 0.5 \%$ ID/g, $p=0.0086)$, and when compared with isotype control radiotracer uptake $(5.4 \pm 0.8 \% \mathrm{ID} / \mathrm{g}$, $p=0.0345$ ) (Figure 3C).

Tumor-to-organ ratios for different xenografts are shown in Table 2, showing the best ratios for [ ${ }^{89} \mathrm{Zr}$ ]Zr-DFO-AMG162 in RANKL positive UM-SCC-22B xenografts (Tables S5-S7).

Table 2. Tumor-to-organ ratio 5 days post injection in mice bearing UM-SCC-22B ([ $\left.{ }^{89} \mathrm{Zr}\right] \mathrm{Zr}-\mathrm{DFO}-$ AMG162 $(n=4)$ and [ $\left.{ }^{89} \mathrm{Zr}\right] \mathrm{Zr-DFO-IgG2}(n=5)$ and HCT-116 $\left(\left[{ }^{89} \mathrm{Zr}\right] \mathrm{Zr}-\mathrm{DFO}-\mathrm{AMG} 162(n=5)\right.$ xenografts. Data is shown below as mean \pm the standard deviation.

\begin{tabular}{cccc}
\hline Tumor-to-Organ Ratio & Blood & Muscle & Bone \\
\hline $\begin{array}{c}\text { UM-SCC-22B RANKL+ } \\
{\left[{ }^{89} \mathrm{Zr}\right] Z r-D F O-A M G 162}\end{array}$ & $0.61 \pm 0.1$ & $8.04 \pm 1.4$ & $1.74 \pm 0.5$ \\
\hline $\begin{array}{c}\text { UM-SCC-22B RANKL+ } \\
{\left[{ }^{89} \mathrm{Zr}\right] Z \text {-DFO-IgG2 }}\end{array}$ & $0.41 \pm 0.1$ & $7.12 \pm 1.2$ & $2.27 \pm 1.2$ \\
\hline $\begin{array}{c}\text { HCT-116 } \text { RANKL- } \\
{\left[{ }^{89} \mathrm{Zr}\right] Z r-D F O-A M G 162}\end{array}$ & $0.46 \pm 0.03$ & $6.53 \pm 1.4$ & $1.42 \pm 0.3$ \\
\hline
\end{tabular}

A high correlation between in vivo radiotracer uptake $(\% \mathrm{ID} / \mathrm{mL})$ and ex vivo measurement (\% ID/g) in UM-SCC-22B xenografts (for $\left[{ }^{89} \mathrm{Zr}\right] \mathrm{Zr}-\mathrm{DFO}-\mathrm{AMG} 162$ and $\left.{ }^{89} \mathrm{Zr}\right] \mathrm{Zr}$ DFO-IgG2) and in HCT-116 xenografts (for [ ${ }^{89} \mathrm{Zr}$ ]Zr-DFO-AMG162) was observed $(r=0.774$, $p=0.0012$; Figure 3D). Taken together these data show specific binding of [ $\left.{ }^{89} \mathrm{Zr}\right] \mathrm{Zr}-\mathrm{DFO}-$ AMG162 to RANKL in human head and neck squamous cancer xenografts UM-SCC-22B, compared to isotype control and a RANKL-negative xenograft.

\subsection{Validation of the Radiotracer Uptake in Tumor Xenografts}

Autoradiography (ARG) and IHC were performed in each group of animals, and the patterns of radiotracer distribution seen on ARG were compared with IHC staining on adjacent tumor sections. ARG of ME-180-RANKL tumor sections with [ $\left.{ }^{89} \mathrm{Zr}\right] \mathrm{Zr}-\mathrm{DFO}-$ AMG162 showed hot spots that could be matched entirely with IHC RANKL stainings (mean $24.0 \pm 6.9 \%$ positively stained tumor area) in adjacent slides (Figure $4 \mathrm{~A}$ ). In the blocking experiments, fewer hot areas could be observed on ARG of ME-180-RANKL tumors, as expected (Figure 4B). However, these regions still demonstrated overlap with RANKL IHC stain (mean $23.8 \pm 4.4 \%$ positively stained tumor area) (Figure S4).

Overall, a lower intensity of uptake was seen on ARG in UM-SCC-22B tumor sections evaluated with [ ${ }^{89} \mathrm{Zr}$ ]Zr-DFO-AMG162 (Figure 4C), but with good spatial congruency with RANKL expression on IHC. In contrast, no overlap between both methods was observed with [ ${ }^{89} \mathrm{Zr}$ ]Zr-DFO-IgG2 uptake (Figure 4D). Quantification of RANKL IHC of UM-SCC-22B xenografts with [ $\left.{ }^{89} \mathrm{Zr}\right] \mathrm{Zr}$-DFO-AMG162 and [ $\left.{ }^{89} \mathrm{Zr}\right] \mathrm{Zr}-\mathrm{DFO}-\mathrm{IgG} 2$ showed a mean of $5.2 \pm 3.1 \%$ and $5.0 \pm 2.0 \%$ positively stained tumor area, respectively. Notably, UM-SCC-22B xenografts expressed high spatial RANKL heterogeneity. HCT-116 IHC slides were completely negative for RANKL stain, with a mean of $0.5 \pm 0.2 \%$ positively stained tumor area (Figure 4E). In both UM-SCC-22B ([ $\left.{ }^{89} \mathrm{Zr}\right] \mathrm{Zr}$-DFO-IgG2, Figure 4D) and HCT116 ([ $\left.{ }^{89} \mathrm{Zr}\right] \mathrm{Zr}-\mathrm{DFO}-\mathrm{AMG} 162$, Figure 4E), radiotracer uptake corresponded mostly with regions of high vasculature and stroma, which is consistent with non-specific EPR uptake (Figure S4). Correlation analysis between RANKL IHC mean \% positive stained tumor area and ex vivo or PET [ ${ }^{89} \mathrm{Zr}$ ]Zr-DFO-AMG162 uptake in all xenografts (blocking excluded) showed a correlation of $r=0.8634(p<0.0001)$ and $r=0.8934(p<0.0001)$, respectively. 
A) [ $\left.{ }^{89} \mathrm{Zr}\right] Z \mathrm{Zr}-\mathrm{DFO}-\mathrm{AMG} 162$ in ME-180-RANKL
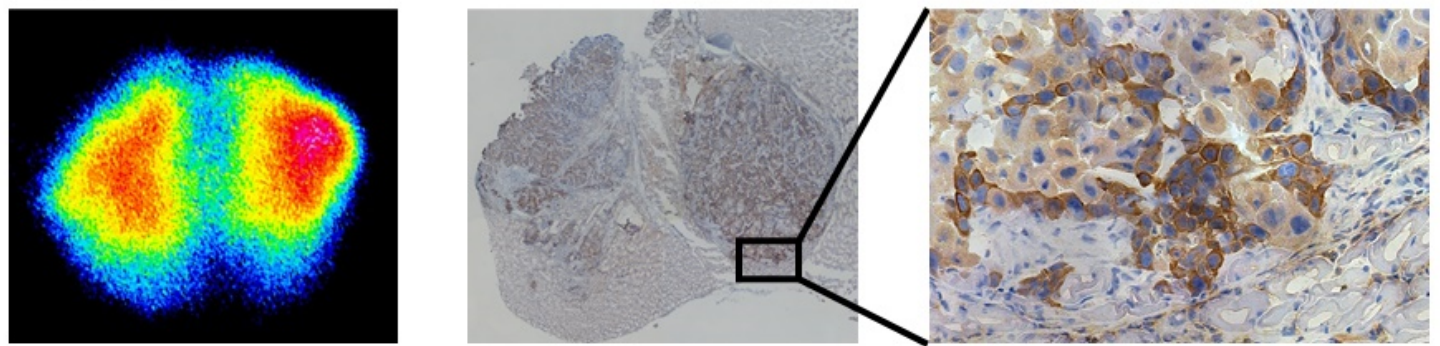

B) [ ${ }^{89} \mathrm{Zr}$ ]Zr-DFO-AMG162 in blocked ME-180-RANKL
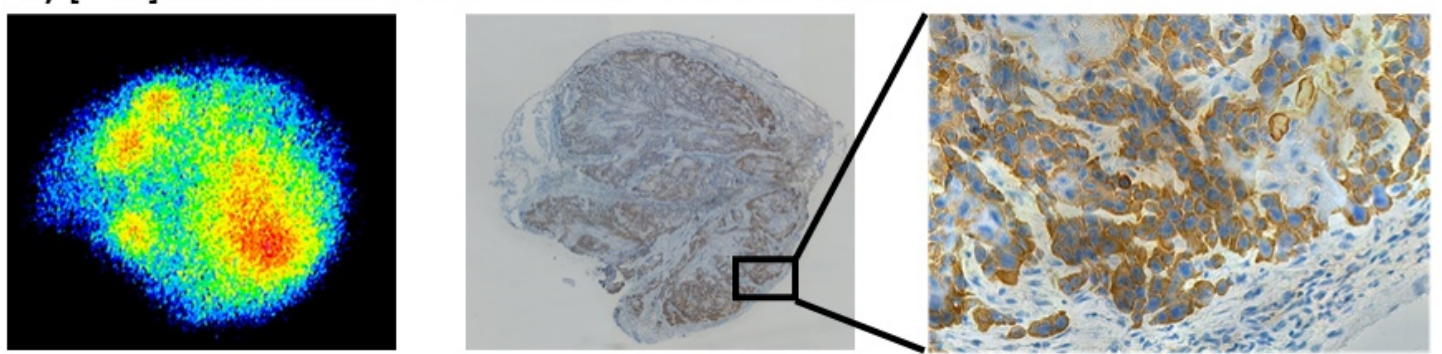

C) $\left[{ }^{89} \mathrm{Zr}\right] \mathrm{Zr}$-DFO-AMG162 UM-SCC-22B
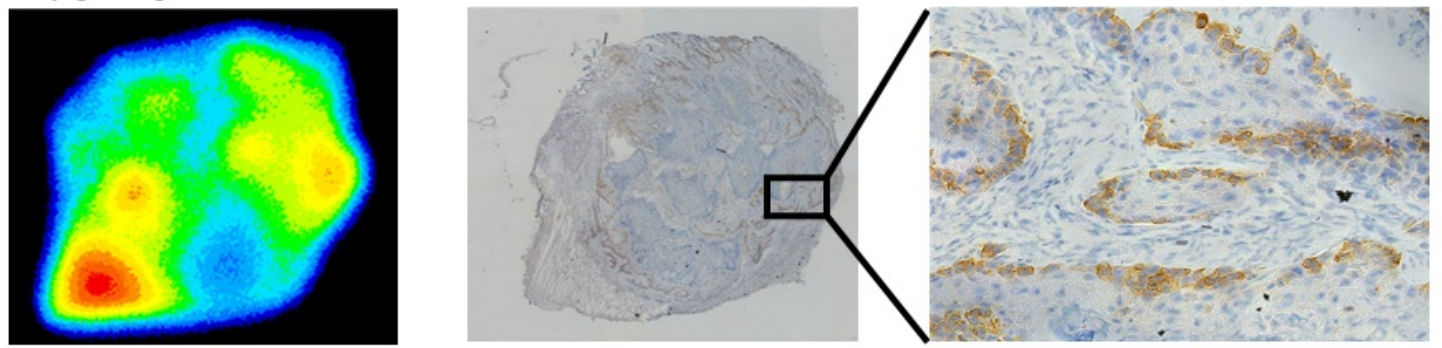

D) $\left[{ }^{89} \mathrm{Zr}\right] \mathrm{Zr}-\mathrm{DFO}-\lg \mathrm{g} 2$ in UM-SCC-22B
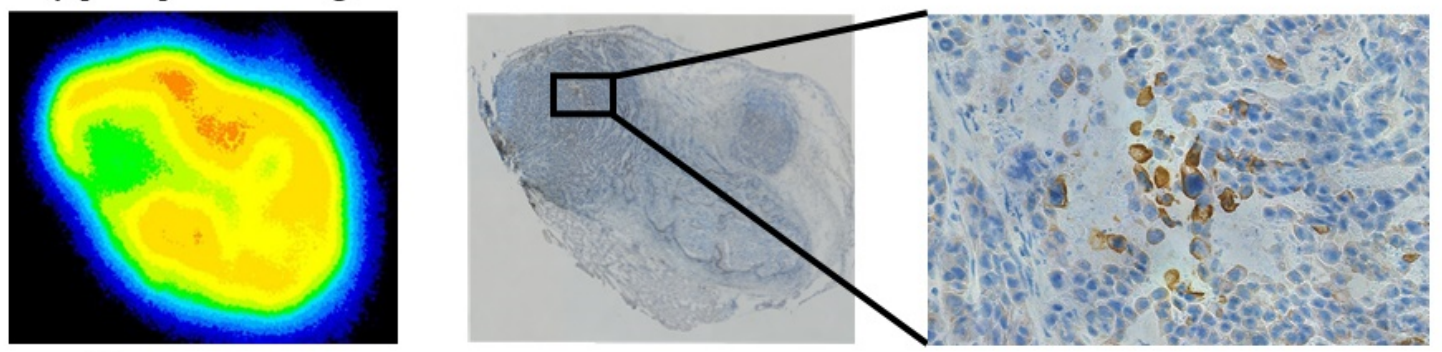

E) [ $\left.{ }^{89} \mathrm{Zr}\right] \mathrm{Zr}-\mathrm{DFO}-\mathrm{AMG} 162$ in HCT-116

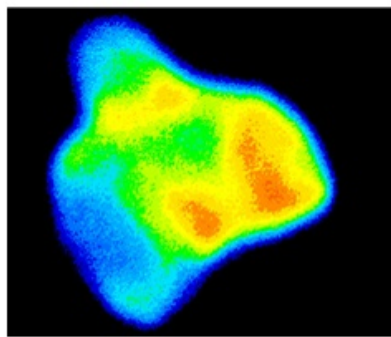

High

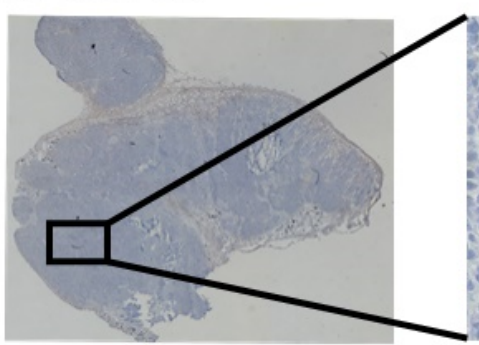

Overview $\times 40$

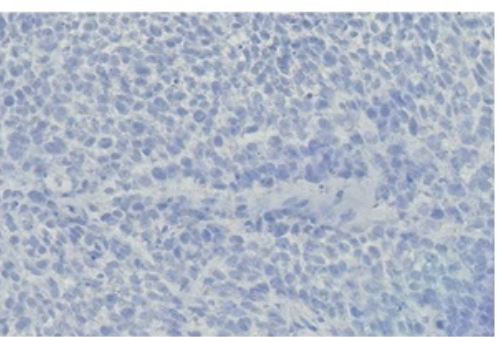

Detail $\times 200$

Figure 4. Autoradiography (High-Low (counts)), adjacent RANKL IHC (brown stain) overview image $(\times 40)$, and detailed RANKL IHC image $(\times 200)$ in xenografts: (A) [ ${ }^{89} \mathrm{Zr}$ ZZr-DFO-AMG162 in ME-180-RANKL, (B) [ $\left.{ }^{89} \mathrm{Zr}\right] \mathrm{Zr}-\mathrm{DFO}-\mathrm{AMG162}$ in blocked ME-180-RANKL, (C) [ $\left.{ }^{89} \mathrm{Zr}\right] \mathrm{Zr}-\mathrm{DFO}-\mathrm{AMG} 162$ in UM-SCC-22B, (D) [ $\left.{ }^{89} \mathrm{Zr}\right] \mathrm{Zr}-\mathrm{DFO}-\mathrm{IgG} 2$ in UM-SCC-22B and (E) $\left[{ }^{89} \mathrm{Zr}\right] \mathrm{Zr}-\mathrm{DFO}-\mathrm{AMG} 162$ in HCT-116. 


\section{Discussion}

The introduction of a RANKL-targeting treatment using the monoclonal antibody denosumab (AMG162) has improved clinical outcomes in patients with various skeletal conditions, including osteoporosis, metastatic bone disease, multiple myeloma, and giant cell tumor of bone [16]. Moreover, data from the Cancer Genome Atlas (TCGA) suggests that RANKL gene expression is associated with patient outcome in multiple cancer types in an explorative analysis of survival (Figure 5) $[17,18]$. This illustrates the potential of antiRANKL therapies and novel methods for RANKL quantification, including immuno-PET.

A

RANKL gene expression

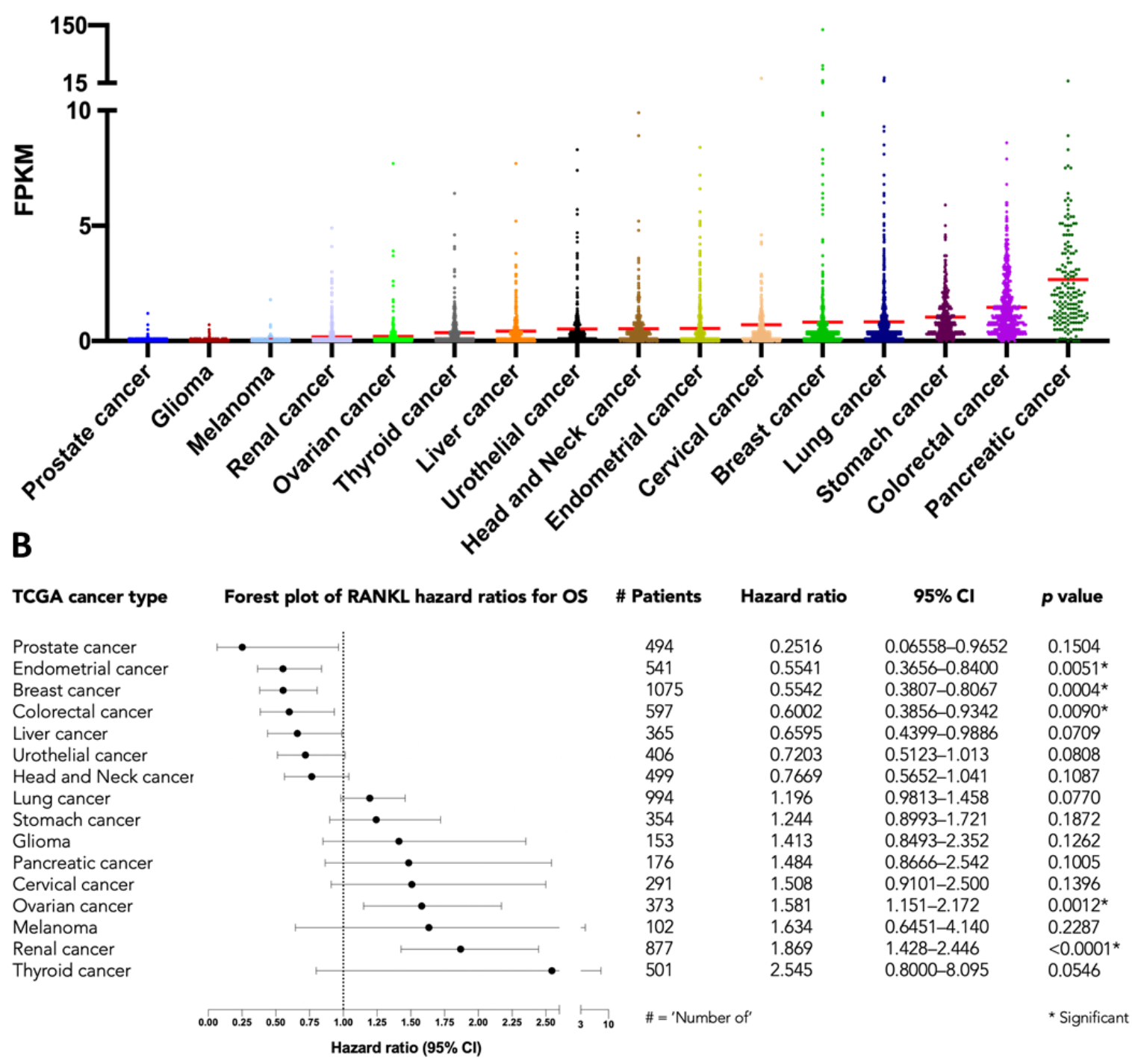

Figure 5. RANKL mRNA expression in 7798 patients with 16 different cancer types, available from The Cancer Genome Atlas (TCGA) database: (A) RANKL gene expression in Fragments Per Kilobase Million (FPKM), with red lines representing the mean, and (B) forest plot of the hazard ratios for overall survival (OS). Hazard ratios and the $95 \%$ confidence interval (CI) were estimated using the logrank method, as implemented in GraphPad.

More recently, the potential for repurposing denosumab as a modulator of the immune response in improving the efficacy of ICI in cancer treatment is actively being explored $[19,20]$. A phase II study in breast cancer patients supports this approach by showing an increase in lymphocytes and CD8+ T-cells in tumors exposed to single-agent denosumab (D-BEYOND; ClinicalTrials.gov Identifier: NCT01864798) [21]. Of note are 
two ongoing randomized trials, one being the CHARLI trial (ClinicalTrials.gov Identifier: NCT03161756) that is a phase Ib/II study including patients with unresectable stage III/IV melanoma treated with nivolumab in combination with four doses of denosumab, with or without ipilimumab (primary end-point: progression-free survival). The POPCORN trial (ACTRN12618001121257) is a phase $\mathrm{Ib} / \mathrm{II}$ translational study including patients with stage IA to IIIA non-small-cell lung cancer receiving neoadjuvant treatment with two doses of nivolumab with or without denosumab (following nivolumab), followed by surgery and as primary end-point translational research into the tumor-immune correlates of combination therapy. Similar translational efforts are ongoing in phase I/II studies in cervical cancer (DICER; ISS20177041) and melanoma (ClinicalTrials.gov Identifier: NCT03620019) [1].

However, both in clinical practice and in the setting of clinical trials, questions remain regarding patient selection, optimal duration, long-term safety, maintenance dose, and sequencing of therapies that include a RANKL inhibitor $[22,23]$. These issues remain largely unaddressed, in part because of a lack of reliable non-invasive biomarkers for RANKL. Moreover, the observation that the benefit of the combination of RANKL and ICI may be sequence-dependent supports the concept of a biomarker that allows sequential assessment without the need for invasive procedures [24]. We initiated the search for an imaging biomarker of RANKL in the TME by radiolabeling AMG161 (IgG1) and AMG162 (IgG2). The difference in isotype showed no impact on in vitro characterization, with both yielding good radiolabeling, stability and unchanged affinity. However, a significant difference could be observed in vivo between both isotypes: [ $\left.{ }^{89} \mathrm{Zr}\right] \mathrm{Zr}$-DFO-AMG161 expressed different levels of radiotracer sequestration in spleen and liver, a phenomenon which could be related to mouse Fc receptor binding. Generally, IgG1 antibodies are more immunoreactive than their IgG2 counterparts and more prone to bind Fc receptors, an effect that is even more pronounced in immunodeficient mice models [25]. Even though the translational significance of this sequestration of the radiotracer for the biodistribution in humans is uncertain, it is an undesirable characteristic that can result in lower target uptake and more rapid metabolization of the tracer. Radiotracers revealed clear $(5-10 \% \mathrm{ID} / \mathrm{g})$ bone uptake, a phenomenon related to instability of the DFO complex, remarkably in patients the unwanted bone uptake is hardly an issue [26]. New chelators with improved characteristics have been developed $\left(\mathrm{DFO}^{*} / \mathrm{HOPO}\right)$ but were not yet commercially available at the start of this study [27]. Currently, AMG162 is an FDA-approved biopharmaceutical used in clinical care, whereas AMG161 is not, and this may limit its potential for successful clinical translation. For these reasons, $\left[{ }^{89} \mathrm{Zr}\right] \mathrm{Zr}-\mathrm{DFO}-\mathrm{AMG} 162$ was selected for further experiments.

The selective uptake of [ ${ }^{89} \mathrm{Zr}$ ]Zr-DFO-AMG162 was demonstrated in RANKL-transduced ME-180 xenografts, with clear visualization on PET and high radiotracer uptake in the xenografts. Subsequent ARG and IHC showed corresponding regions with radiotracer uptake and staining, respectively. Moreover, a control blocking experiment reduced the radiotracer uptake demonstrating the specific uptake of the radiotracer.

Subsequent experiments were performed on patient-derived cell lines, UM-SCC-22B (RANKL positive) and HCT-116 (negative control). The RANKL positive cell line UMSCC-22B was of interest since both membranes bound and soluble RANKL expression was reported. However, prior to the start of the study RNA RANKL expression was not assessed in different cell lines to select the highest RANKL expression cell line and is a limitation of the study.

$\left[{ }^{89} \mathrm{Zr}\right] \mathrm{Zr}-\mathrm{DFO}-\mathrm{AMG} 162$ showed specific uptake of on immuno-PET in UM-SCC-22B xenografts and not of the radiolabeled isotype control [ $\left.{ }^{89} \mathrm{Zr}\right] \mathrm{Zr}-\mathrm{DFO}-\mathrm{IgG}$. While we could visualize physiologically relevant amounts of tumor derived RANKL in the TME with [ ${ }^{89} \mathrm{Zr}$ ]Zr-DFO-AMG162, the RANKL expression of UM-SCC-22B was substantially lower compared to the transduced ME-180-RANKL cell line. In contrast, [ $\left.{ }^{89} \mathrm{Zr}\right] \mathrm{Zr}-\mathrm{DFO}-\mathrm{AMG} 162$ uptake was significantly lower in HCT-116 xenografts (a non-RANKL expressing model) compared to UM-SCC-22B xenografts (a RANKL expressing cell line), supporting the specificity of tracer uptake. While the overall differences in mean SUV of [ $\left.{ }^{89} \mathrm{Zr}\right] \mathrm{Zr}$-DFO-AMG162 
uptake between UM-SCC-22B and HCT-116 xenografts or over isotype control were low, remarkable differences in regional uptake were evident, confirming the considerable heterogeneity of RANKL in the TME, which may be missed by other sampling techniques (IHC). Autoradiography and immunohistochemistry were used to explore the contribution of RANKL heterogeneity on overall uptake. This showed convincing spatial congruency of $\left[{ }^{89} \mathrm{Zr}\right] \mathrm{Zr}$-DFO-AMG162 and RANKL expression in UM-SCC-22B xenografts. In contrast, autoradiography only demonstrated limited overlap in areas with high vasculature or stroma when using [ ${ }^{89} \mathrm{Zr}$ ]Zr-DFO-IgG2 (in UM-SCC-22B xenografts) or [ $\left.{ }^{89} \mathrm{Zr}\right] \mathrm{Zr}$-DFO-AMG162 (in HCT-116 xenografts), suggesting non-specific uptake. Indeed, the large size of antibodies $(\sim 150 \mathrm{kDa})$ represents an intrinsic limitation for efficient tumor diffusion, and due to their high avidity, they remain close to the periphery of the vasculature [28]. In addition, the long-blood half-lives of several days to weeks allows antibody-based radiotracers to achieve high uptake-values in targeted tissues, but simultaneously leads to elevated overall non-specific accumulation [29].Taken together, these data illustrate the potential benefits of immuno-PET for in vivo RANKL assessment compared to other sampling techniques, such as biopsies that are prone to error due to sampling bias or serum assays that are only able to provide a global biomarker quantification. In addition, immuno-PET has the unique capability of non-invasively visualizing actual drug-delivery to the TME.

Importantly, it is noted that while murine RANKL shares $83 \%$ sequence homology with human RANKL, the anti-RANKL antibodies used in our experiments have no affinity for murine RANKL [30]. For the purpose of our study, this difference is not of importance, but evidence does implicate the host-derived RANKL in the TME [31]. Therefore, further preclinical work using $\left[{ }^{89} \mathrm{Zr}\right] \mathrm{Zr}$-DFO-AMG162 to elucidate the tumor and host interactions in the TME will require more translationally appropriate clinical models. For example, the use of transgenic models and humanized mice models may better reflect the human TME and recapitulate the complex interactions of RANKL between the tumor and surrounding cells [32,33]. Finally, a more human-like TME may impact the levels of tumor-derived RANKL expression, resulting in improved imaging characteristics.

\section{Conclusions}

In conclusion, we describe for the first time in vivo assessment of RANKL expression in the TME using immuno-PET imaging. Our results suggest that RANKL imaging offers advantages over more traditional approaches for longitudinal tumor characterization and merits further investigation. $\left[{ }^{89} \mathrm{Zr}\right] \mathrm{Zr}-\mathrm{DFO}-\mathrm{AMG} 162$ showed favorable stability, high binding affinity, and specific tumor uptake with very good visual agreement to the spatial distribution of RANKL in the TME as assessed with histology, supporting further translation to evaluate tumor RANKL distribution in patients.

Supplementary Materials: The following are available online at https: / www.mdpi.com/article/ 10.3390 / cancers13092166/s1, Figure S1: Mass spectrometry bioconjugates, Figure S2: Ligand assay, Figure S3: Stability of radio-immunoconjugates in vitro, Figure S4: IHC quantification, Table S1: Ex vivo biodistribution (mean \pm 1 standard deviation $\%$ ID/g) in healthy CD-1 nude mice $(n=4)$ at 1, 2, 3, 4, 7 days post injection of [ ${ }^{89} \mathrm{Zr}$ ]Zr-DFO-AMG162, Table S2: Ex vivo biodistribution (mean \pm 1 standard deviation \% ID/g) in healthy CD-1 nude mice $(n=4)$ at $1,2,3,4,7$ days post injection of $\left[{ }^{89} \mathrm{Zr}\right] \mathrm{Zr}-\mathrm{DFO}-\mathrm{AMG161}$, Table S3: Ex vivo biodistribution (mean \pm 1 standard deviation $\%$ ID/g) and tumor/organ ratio in healthy CD-1 nude mice $(n=5)$ at 5 days post injection of $\left[{ }^{89} \mathrm{Zr}\right] \mathrm{Zr}$ DFO-AMG162 in ME-180-RANKL xenografts, Table S4: Ex vivo biodistribution (mean \pm 1 standard deviation $\% \mathrm{ID} / \mathrm{g})$ and tumor/organ ratio in healthy CD-1 nude mice $(n=5)$ at 5 days post injection of [ ${ }^{89} \mathrm{Zr}$ ]Zr-DFO-AMG162 blocked ME-180-RANKL xenografts, Table S5: Ex vivo biodistribution (mean \pm 1 standard deviation $\% \mathrm{ID} / \mathrm{g}$ ) and tumor/organ ratio in healthy CD-1 nude mice $(n=4)$ at 5 days post injection [ ${ }^{89} \mathrm{Zr}$ Zr-DFO-AMG162 in UM-SCC-22B xenografts, Table S6: Ex vivo biodistribution (mean \pm 1 standard deviation $\% \mathrm{ID} / \mathrm{g}$ ) and tumor/organ ratio in healthy CD-1 nude mice $(n=5)$ at 5 days post injection $\left[{ }^{89} \mathrm{Zr}\right.$ ]Zr-DFO-IgG2 in UM-SCC-22B xenografts, Table S7: Ex vivo biodistribution (mean \pm 1 standard deviation $\% \mathrm{ID} / \mathrm{g}$ ) and tumor/organ ratio in healthy CD-1 nude mice $(n=5)$ at 5 days post injection [ ${ }^{89} \mathrm{Zr}$ ]Zr-DFO-AMG162 in HCT-116 xenografts. 
Author Contributions: Conceptualization, J.D., C.V., F.E. and T.V.d.W.; data curation, J.D.W.; formal analysis, J.D.; funding acquisition, T.V.d.W.; investigation, J.D.W., Y.V. and F.E.; methodology, J.D.W., C.V., F.E. and T.V.d.W.; project administration, T.V.d.W.; resources, T.V.d.W.; supervision, F.E. and T.V.d.W.; visualization, J.D.W., F.E. and T.V.d.W.; writing-original draft, J.D.W.; writing-review and editing, J.D.W., C.V., Y.V., J.D.W., K.Z., P.A.v.D., F.E. and T.V.d.W. All authors contributed to the manuscript and have read and agreed to the published version of the manuscript.

Funding: This work was funded by the University of Antwerp (BOF DOCPRO/FFB180183). Y.V. received funding from the Emmanuel van der Schueren research grant (CS 16628) of Kom op tegen Kanker (Stand up to Cancer), the Flemish cancer society and is a research fellow of the Research Foundation Flanders (FWO; 1S69721N). F.E. is supported by the Research Foundation Flanders (FWO; $12 \mathrm{~T} 8821 \mathrm{~N})$. Master materials and funding agreement (2014634575) with Amgen Inc. was established providing antibodies AMG161, AMG162 and recombinant protein huRANKL.

Institutional Review Board Statement: The study was conducted according to the guidelines of the Declaration of Helsinki and approved by the Institutional Review Board of University of Antwerp (2018-48, approved 17 September 2018).

Informed Consent Statement: Not applicable.

Data Availability Statement: Data is contained within the article or supplementary material.

Acknowledgments: We want to acknowledge Dominique Vanderghinste and Stef de Lombaerde (Antwerp University Hospital) for their input in ${ }^{89} \mathrm{Zr}$-immuno-PET radiolabeling. In addition, we want to thank Philippe Joye, Caroline Berghmans, Demi Rotthier and Annemie Van Eetveldt (Molecular Imaging Center Antwerp) for their help in animal handling and PET scans.

Conflicts of Interest: No potential conflicts of interest relevant to this article exist.

\section{References}

1. van Dam, P.A.; Verhoeven, Y.; Jacobs, J.; Wouters, A.; Tjalma, W.; Lardon, F.; Van den Wyngaert, T.; Dewulf, J.; Smits, E.; Colpaert, C.; et al. RANK-RANKL Signaling in Cancer of the Uterine Cervix: A Review. Int. J. Mol. Sci. 2019, 20, 2183. [CrossRef]

2. $\quad$ Lacey, D.L.; Boyle, W.J.; Simonet, W.S.; Kostenuik, P.J.; Dougall, W.C.; Sullivan, J.K.; San Martin, J.; Dansey, R. Bench to bedside: Elucidation of the OPG-RANK-RANKL pathway and the development of denosumab. Nat. Rev. Drug Discov. 2012, 11, 401-419. [CrossRef]

3. Kong, Y.Y.; Yoshida, H.; Sarosi, I.; Tan, H.L.; Timms, E.; Capparelli, C.; Morony, S.; Oliveira-dos-Santos, A.J.; Van, G.; Itie, A.; et al. OPGL is a key regulator of osteoclastogenesis, lymphocyte development and lymph-node organogenesis. Nature 1999, 397, 315-323. [CrossRef]

4. Chawla, S.; Blay, J.Y.; Rutkowski, P.; Le Cesne, A.; Reichardt, P.; Gelderblom, H.; Grimer, R.J.; Choy, E.; Skubitz, K.; Seeger, L.; et al. Denosumab in patients with giant-cell tumour of bone: A multicentre, open-label, phase 2 study. Lancet Oncol. 2019, 20, 1719-1729. [CrossRef]

5. Cummings, S.R.; San Martin, J.; McClung, M.R.; Siris, E.S.; Eastell, R.; Reid, I.R.; Delmas, P.; Zoog, H.B.; Austin, M.; Wang, A.; et al. Denosumab for prevention of fractures in postmenopausal women with osteoporosis. N. Engl. J. Med. 2009, 361, 756-765. [CrossRef] [PubMed]

6. $\quad$ Lipton, A.; Fizazi, K.; Stopeck, A.T.; Henry, D.H.; Brown, J.E.; Yardley, D.A.; Richardson, G.E.; Siena, S.; Maroto, P.; Clemens, M.; et al. Superiority of denosumab to zoledronic acid for prevention of skeletal-related events: A combined analysis of 3 pivotal, randomised, phase 3 trials. Eur. J. Cancer 2012, 48, 3082-3092. [CrossRef] [PubMed]

7. Schramek, D.; Leibbrandt, A.; Sigl, V.; Kenner, L.; Pospisilik, J.A.; Lee, H.J.; Hanada, R.; Joshi, P.A.; Aliprantis, A.; Glimcher, L.; et al. Osteoclast differentiation factor RANKL controls development of progestin-driven mammary cancer. Nature 2010, 468, 98-102. [CrossRef] [PubMed]

8. Ahern, E.; Smyth, M.J.; Dougall, W.C.; Teng, M.W.L. Roles of the RANKL-RANK axis in antitumour immunity-implications for therapy. Nat. Rev. Clin. Oncol. 2018, 15, 676-693. [CrossRef]

9. Dougall, W.C.; Roman Aguilera, A.; Smyth, M.J. Dual targeting of RANKL and PD-1 with a bispecific antibody improves anti-tumor immunity. Clin. Transl. Immunol. 2019, 8, e01081. [CrossRef]

10. Jia, Y.; Liu, L.; Shan, B. Future of immune checkpoint inhibitors: Focus on tumor immune microenvironment. Ann. Transl. Med. 2020, 8, 1095. [CrossRef]

11. Rachner, T.D.; Kasimir-Bauer, S.; Gobel, A.; Erdmann, K.; Hoffmann, O.; Browne, A.; Wimberger, P.; Rauner, M.; Hofbauer, L.C.; Kimmig, R.; et al. Prognostic Value of RANKL/OPG Serum Levels and Disseminated Tumor Cells in Nonmetastatic Breast Cancer. Clin. Cancer Res. 2019, 25, 1369-1378. [CrossRef] [PubMed]

12. Rogers, A.; Eastell, R. Circulating osteoprotegerin and receptor activator for nuclear factor kappaB ligand: Clinical utility in metabolic bone disease assessment. J. Clin. Endocrinol. Metab. 2005, 90, 6323-6331. [CrossRef] [PubMed] 
13. Maggi, A.; Ruivo, E.; Fissers, J.; Vangestel, C.; Chatterjee, S.; Joossens, J.; Sobott, F.; Staelens, S.; Stroobants, S.; Van Der Veken, P.; et al. Development of a novel antibody-tetrazine conjugate for bioorthogonal pretargeting. Org. Biomol. Chem. 2016, 14, 7544-7551. [CrossRef] [PubMed]

14. Price, E.W.; Carnazza, K.E.; Carlin, S.D.; Cho, A.; Edwards, K.J.; Sevak, K.K.; Glaser, J.M.; de Stanchina, E.; Janjigian, Y.Y.; Lewis, J.S. (89)Zr-DFO-AMG102 Immuno-PET to Determine Local Hepatocyte Growth Factor Protein Levels in Tumors for Enhanced Patient Selection. J. Nucl. Med. 2017, 58, 1386-1394. [CrossRef] [PubMed]

15. Varghese, F.; Bukhari, A.B.; Malhotra, R.; De, A. IHC Profiler: An open source plugin for the quantitative evaluation and automated scoring of immunohistochemistry images of human tissue samples. PLoS ONE 2014, 9, e96801. [CrossRef]

16. Dewulf, J.; Vangestel, C.; Verhoeven, Y.; van Dam, P.; Elvas, F.; Van den Wyngaert, T.; Clezardin, P. Bone metastases in the era of targeted treatments: Insights from molecular biology. Q. J. Nucl Med. Mol. Imaging 2019, 63, 98-111. [CrossRef]

17. Uhlen, M.; Zhang, C.; Lee, S.; Sjostedt, E.; Fagerberg, L.; Bidkhori, G.; Benfeitas, R.; Arif, M.; Liu, Z.; Edfors, F.; et al. A pathology atlas of the human cancer transcriptome. Science 2017, 357. [CrossRef]

18. TCGA; THPA. The Human Protein Atlas (TCGA). Available online: http:/ /www.proteinatlas.org (accessed on 13 January 2021).

19. Simatou, A.; Sarantis, P.; Koustas, E.; Papavassiliou, A.G.; Karamouzis, M.V. The Role of the RANKL/RANK Axis in the Prevention and Treatment of Breast Cancer with Immune Checkpoint Inhibitors and Anti-RANKL. Int. J. Mol. Sci. 2020, 21, 7570. [CrossRef]

20. van Dam, P.A.; Verhoeven, Y.; Trinh, X.B.; Wouters, A.; Lardon, F.; Prenen, H.; Smits, E.; Baldewijns, M.; Lammens, M. RANK/RANKL signaling inhibition may improve the effectiveness of checkpoint blockade in cancer treatment. Crit. Rev. Oncol. Hematol. 2019, 133, 85-91. [CrossRef]

21. Gomez-Aleza, C.; Nguyen, B.; Yoldi, G.; Ciscar, M.; Barranco, A.; Hernandez-Jimenez, E.; Maetens, M.; Salgado, R.; Zafeiroglou, M.; Pellegrini, P.; et al. Inhibition of RANK signaling in breast cancer induces an anti-tumor immune response orchestrated by CD8+ T cells. Nat. Commun. 2020, 11, 6335. [CrossRef]

22. Li, H.; Gao, J.; Gao, Y.; Lin, N.; Zheng, M.; Ye, Z. Denosumab in Giant Cell Tumor of Bone: Current Status and Pitfalls. Front. Oncol. 2020, 10, 580605. [CrossRef]

23. Otto, S.; Pautke, C.; Van den Wyngaert, T.; Niepel, D.; Schiodt, M. Medication-related osteonecrosis of the jaw: Prevention, diagnosis and management in patients with cancer and bone metastases. Cancer Treat. Rev. 2018, 69, 177-187. [CrossRef] [PubMed]

24. Ahern, E.; Harjunpaa, H.; O’Donnell, J.S.; Allen, S.; Dougall, W.C.; Teng, M.W.L.; Smyth, M.J. RANKL blockade improves efficacy of PD1-PD-L1 blockade or dual PD1-PD-L1 and CTLA4 blockade in mouse models of cancer. Oncoimmunology 2018, 7, e1431088. [CrossRef] [PubMed]

25. Sharma, S.K.; Chow, A.; Monette, S.; Vivier, D.; Pourat, J.; Edwards, K.J.; Dilling, T.R.; Abdel-Atti, D.; Zeglis, B.M.; Poirier, J.T.; et al. Fc-Mediated Anomalous Biodistribution of Therapeutic Antibodies in Immunodeficient Mouse Models. Cancer Res. 2018, 78, 1820-1832. [CrossRef] [PubMed]

26. Bensch, F.; Smeenk, M.M.; van Es, S.C.; de Jong, J.R.; Schroder, C.P.; Oosting, S.F.; Lub-de Hooge, M.N.; Menke-van der Houven van Oordt, C.W.; Brouwers, A.H.; Boellaard, R.; et al. Comparative biodistribution analysis across four different (89)Zr-monoclonal antibody tracers-The first step towards an imaging warehouse. Theranostics 2018, 8, 4295-4304. [CrossRef]

27. Raave, R.; Sandker, G.; Adumeau, P.; Jacobsen, C.B.; Mangin, F.; Meyer, M.; Moreau, M.; Bernhard, C.; Da Costa, L.; Dubois, A.; et al. Direct comparison of the in vitro and in vivo stability of DFO, DFO* and DFOcyclo* for (89)Zr-immunoPET. Eur. J. Nucl. Med. Mol. Imaging 2019, 46, 1966-1977. [CrossRef]

28. Leelawattanachai, J.; Kwon, K.W.; Michael, P.; Ting, R.; Kim, J.Y.; Jin, M.M. Side-by-Side Comparison of Commonly Used Biomolecules That Differ in Size and Affinity on Tumor Uptake and Internalization. PLoS ONE 2015, 10, e0124440. [CrossRef]

29. Debie, P.; Lafont, C.; Defrise, M.; Hansen, I.; van Willigen, D.M.; van Leeuwen, F.W.B.; Gijsbers, R.; D’Huyvetter, M.; Devoogdt, N.; Lahoutte, T.; et al. Size and affinity kinetics of nanobodies influence targeting and penetration of solid tumours. J. Control. Release 2020, 317, 34-42. [CrossRef]

30. Wong, B.R.; Josien, R.; Lee, S.Y.; Sauter, B.; Li, H.L.; Steinman, R.M.; Choi, Y. TRANCE (tumor necrosis factor [TNF]-related activation-induced cytokine), a new TNF family member predominantly expressed in T cells, is a dendritic cell-specific survival factor. J. Exp. Med. 1997, 186, 2075-2080. [CrossRef]

31. Morrissey, C.; Kostenuik, P.L.; Brown, L.G.; Vessella, R.L.; Corey, E. Host-derived RANKL is responsible for osteolysis in a C4-2 human prostate cancer xenograft model of experimental bone metastases. BMC Cancer 2007, 7, 148. [CrossRef]

32. Kostenuik, P.J.; Nguyen, H.Q.; McCabe, J.; Warmington, K.S.; Kurahara, C.; Sun, N.; Chen, C.; Li, L.; Cattley, R.C.; Van, G.; et al. Denosumab, a fully human monoclonal antibody to RANKL, inhibits bone resorption and increases BMD in knock-in mice that express chimeric (murine/human) RANKL. J. Bone Miner. Res. 2009, 24, 182-195. [CrossRef]

33. Rinotas, V.; Niti, A.; Dacquin, R.; Bonnet, N.; Stolina, M.; Han, C.Y.; Kostenuik, P.; Jurdic, P.; Ferrari, S.; Douni, E. Novel genetic models of osteoporosis by overexpression of human RANKL in transgenic mice. J. Bone Miner. Res. 2014, 29, 1158-1169. [CrossRef] 